\title{
Perceptions of Teachers on Psychosocial Life Skills in the Secondary School SiSwati Curriculum
}

\author{
Oloyede, O. I. , , Sihlongonyane, T \\ Department of Curriculum and Teaching, Faculty of Education, University of Swaziland, Swaziland
}

Copyright $(2017$ by authors, all rights reserved. Authors agree that this article remains permanently open access under the terms of the Creative Commons Attribution License 4.0 International License

\begin{abstract}
The study investigated the perceptions of teachers on psycho - social life skills in the secondary school siSwati curriculum. The study set out to achieve three objectives and answer three research questions which were meant to establish the teachers' level of perception of life skills. A mixed method design which combined qualitative and quantitative research was used. Questionnaire and semi structured discursively oriented interviews were used to collect data. A simple random sampling procedure was employed to get twenty siSwati teachers from four schools in the Shiselweni region in Swaziland to respond to questionnaires. The follow up semi structured discursively oriented interviews were used to collect data from twelve teachers. The study established that most teachers were aware of life skills found in the siSwati curriculum but the level of perception was low. The research findings indicated that siSwati teachers were less involved in the promotion of life skills mostly because of lack of knowledge on how to integrate life skills in the siSwati lessons. Conclusions drawn from findings were that lack of time, life skills materials, and teacher training on life skills teaching were the challenges that hinders life skills teaching. Based on the findings it was recommended that in-service workshops for the siSwati teachers on the teaching of life skills be organised, teaching materials especially teacher's guide be provided, and time should be allocated on the schools time table for life skills.
\end{abstract}

Keywords Cognitive Skills, Personal Skill, Interpersonal Skills, Perceptions and Psychosocial Life Skills

\section{Introduction}

Research has indicated that the cardinal reasoning for the introduction of psychosocial life skills in schools curriculum was to bridge the gap between knowledge and behaviour. However, even with life skills education in the curriculum in secondary schools in Swaziland, early sexual involvement and early marriages, delinquency, drug and substance abuse persist among the youth. This state of affairs combined with high level of poverty especially in rural areas and unemployment have greatly contributed to increased school dropouts, and a decline in academic performance in the country. Reassessing the perceptions of teachers on psychosocial life skills in the secondary school siSwati curriculum, could go a long way in reducing or remedying such vices in the secondary schools.

\section{Background and Setting}

Psychosocial skills development is clearly a key foundation for school success. Students who lack appropriate psychosocial skills can be filled with self-doubt and sadness that they are unable to fully attend to daily expectations in school. If teachers hope to help students meet their academic potential, attention must be given to their psychosocial well-being. Children preoccupied with interpersonal conflict unable to make the friends they want, consumed with other emotional tension, not only engage in maladaptive behaviours but are also less able to focus on the demands of the classroom (WHO, 1997).

Many teachers and parents have observed that, learners who are given clear behavioural standards and social skills, allowed to feel safe, valued, and confident, will exhibit better school behaviour and learn more as well (Shriver \& Weissberg, 2005).

'Paying attention to students' non -academic needs is a key ingredient in schools' efforts to meet today's high academic expectations' (Stipek, 2006).

Vihar (2011) states that, life skills include psychosocial competencies and interpersonal skills that help people make informed decisions, solve problems, think critically and creatively, communicate effectively, build healthy relationships, empathize with others, cope with managing their lives in a healthy and productive manner.

Francis (2007) points out that, nowadays a large number of adolescents engage in anti-social activities which creates a lot of social problems like alcoholism, drug abuse, sexual abuse, smoking, early pregnancy and many more. Life skills education is based on the assumption that when young people are able to rise above emotional impasses arising from daily conflicts, entangled relationships and peer pressure, they are less likely to resort to anti- social or high risk behaviours.

A sound curriculum is at the heart of a quality education. A curriculum needs to be responsive to emerging issues (UNICEF, 2000). It will often be necessary to incorporate 
new agenda into curriculum. The principal way to do this is to integrate (mainstream) skills, attitudes and knowledge that will bring about desired behaviours related to these issues into the key learning areas of the curriculum. Life skills learning need to be included in the curricula and not delivered as separate, stand-alone programmes except where conditions may require. According to the Education Sector policy (2011) the vision of the secondary education is to provide a flexible responsive and integrated curriculum that will satisfy world class learning standards comparable with higher and further education and the world of work.

WHO (1997) defines psychosocial life skills as a person's ability to deal with the demands and challenges of everyday life. It is a person's ability to maintain a state of mental wellbeing and to demonstrate this in adaptive and positive behaviour while interacting with others in his/her culture and environment. In its recent efforts to develop a guiding framework for life skills education, UNICEF (2010) has consolidated the various sets of core life skills drawn up by $\mathrm{UN}$ agencies and other organisations under three broad categories of "generic life skills." These are:

- Cognitive - critical thinking and problem solving skills for responsive decision- making.

- Personal - skills for awareness and drive and for selfmanagement; and

- Inter-personal - skills for communication, negotiation, cooperation and teamwork, and for inclusion, empathy and advocacy.

According to WHO (1999) initiatives to develop and implement life skills education in schools have been undertaken in many countries around the world. The need for life skills education is highlighted in the convention of rights of the child and a number of international recommendations. The Jomtien Declaration of 1990 denoted life skills as essential learning tools and basic learning content required by human beings to be able to survive to develop their full capabilities and to improve the quality of their lives. The Dakar Framework for action (2000) encompasses in addition, acquisition of knowledge, values, attitudes and skills. At the heart of life skills education is the learning of psychosocial life skills. Life skills education is aimed at facilitating the development of psychosocial skills that are required to deal effectively with the demands and challenges of everyday life (WHO, 1997). This study therefore aimed at finding out what the siSwati curriculum is doing to help the young people at secondary school develop their psychosocial competencies as they will be leaving school soon.

\section{Statement of the Problem}

Psychosocial life skills are required by every child to be able to deal effectively with the demands and challenges of everyday life. The Swazi education system recognises the importance of life skills, hence one of the aims of Swaziland secondary education is to develop life skills such as: problem -solving, critical thinking, communication, enquiry, team work, and to be adaptable in a changing world (World Data on Education in Swaziland (2010/11). SiSwati being one of the core subjects in the Swaziland General Certificate of Secondary Education (SGCSE) has psychosocial life skills embedded in the curriculum for every Swazi learner. This research sought to find out how teachers perceive the life skills found in the secondary school siSwati curriculum. This would help the teachers realise the importance of implementing these life skills in the teaching and learning process.

\section{The following Research Questions were answered by this study:}

What are the perceptions of secondary school teachers on the;

1. Cognitive life skills in the siSwati curriculum?

2. Personal life skills in the siSwati curriculum?

3. Interpersonal life skills in the siSwati curriculum?

\section{Analysis of SiSwati Curriculum for Elements of Psychosocial Life Skills}

World data on education in Swaziland (2010/11) states that teaching using the SGCSE syllabus started in January 2010 and the first examination for the subjects under this syllabus was organised in 2011. It further states that, secondary education aims at enabling learners to acquire knowledge, develop confidence and ability to assess their personal strengths and weaknesses and be realistic in choosing appropriate career/employment opportunities and or further education and training. Another aim of the secondary education is to develop desirable attitudes and behavioural patterns in interacting with the environment and their fellow men in a respective and tolerant manner. To develop life skills such as problem- solving, critical thinking, communication, enquiry, team work and be adaptable in a changing world.

The National Secondary school Curriculum, states that learners will be given the opportunity to develop essential skills which will overlap across the entire range of subjects studied. These skills are:

a) communication and language skills

b) numeracy skills: mathematical ideas, techniques and applications

c) problem- solving skills

d) technological awareness and application

e) critical thinking skills

f) work and study skills

g) independent learning

h) working with others

Table 1 below shows part of the siSwati syllabus where life skills are embedded. 
Table 1. The SiSwati Curriculum Contents and the life skills embedded

\begin{tabular}{|c|c|c|}
\hline \multicolumn{2}{|c|}{ TOPIC: LANGUAGE SKILLS AND USAGE - Reading and Writing } & \\
\hline $\begin{array}{l}\text { GENERAL OBJECTIVES } \\
\text { All learners will: } \\
\text { - } \quad \text { develop a culture of reading for } \\
\text { varying purposes using a range of } \\
\text { reading techniques to effectively } \\
\text { analyse text. } \\
\text { use standard siSwati to develop } \\
\text { creative writing skills for various } \\
\text { forms writing. } \\
\text { critically interpret instructions and } \\
\text { other forms of stimuli. }\end{array}$ & $\begin{array}{l}\text { COMPETENCIES } \\
\text { All learners should be able to: } \\
\text { Read critically and respond to materials written in SiSwati; } \\
\text { Create original work in all writing; } \\
\text { Detect that a particular instruction has a certain effect/outcome or } \\
\text { result ; } \\
\text { Use material appropriately for various purposes; } \\
\text { Critically interpret instructions and other forms of stimuli; } \\
\text { Give precise written responses in standard SiSwati; } \\
\text { Make inferences on what is read or seen; } \\
\text { Show sensitivity to a particular audience or situation; } \\
\text { Demonstrate competency in punctuation and spelling; } \\
\text { Write accurate complex sentences; } \\
\text { Employ varied sentence structure; }\end{array}$ & $\begin{array}{l}\text { LIFE SKILLS } \\
\text { Critical thinking } \\
\text { Creative thinking problem } \\
\text { solving } \\
\text { Creative thinking } \\
\text { Critical thinking } \\
\text { Problem solving } \\
\text { Empathy } \\
\text { Effective communicating }\end{array}$ \\
\hline \multicolumn{3}{|c|}{ GENERAL OBJECTIVES COMPETENCIES LIFE SKILLS } \\
\hline $\begin{array}{l}\text { All learners will: } \\
\text { analyse and critically evaluate } \\
\text { their culture. } \\
\text { trace the development of cultural } \\
\text { practices in their communities. }\end{array}$ & $\begin{array}{l}\text { Interpret songs, family and traditional poems; } \\
\text { Account for changes in traditional ceremonies, including funerals, and } \\
\text { manner of respect; } \\
\text { Discuss the process of acquiring land traditionally, food taboos } \\
\text { Devise strategies for ensuring the protection and conversation of the } \\
\text { culture; } \\
\text { Discuss and trace the history that is reflected in songs and family } \\
\text { praise names; } \\
\text { Analyse and critically evaluate songs, community laws, traditional } \\
\text { poems, traditional ceremonies and funeral proceedings. } \\
\text { Describe medicine value of some of the indigenous food. } \\
\text { Explore ways expressing grievances in traditional settings. }\end{array}$ & $\begin{array}{l}\text { Critical thinking } \\
\text { Problem solving } \\
\text { Negotiation/ refusal skills } \\
\text { Effective communication } \\
\text { Creative thinking } \\
\text { Critical thinking }\end{array}$ \\
\hline \multicolumn{3}{|c|}{$\begin{array}{l}\text { Some of the siSwati curriculum contents and the life skills embedded Topic: TRADITIONAL LITERATURE- } \\
\text { Songs, Traditional Poems, Family/Clan Praises, Idioms }\end{array}$} \\
\hline $\begin{array}{l}\text { GENERAL OBJECTIVES } \\
\text { All learners will: } \\
\text { examine individual features of } \\
\text { literary works in depth and in } \\
\text { detail. } \\
\text { show understanding of the } \\
\text { purpose of writing, the author's } \\
\text { attitude and style. }\end{array}$ & $\begin{array}{l}\text { COMPETENCIES } \\
\text { All learners should be able to: } \\
\text { Determine the overall meaning of a text; } \\
\text { Summarise, explain and evaluate materials from a text; } \\
\text { Determine the author's implicit attitude; } \\
\text { Compare the writing styles of different authors; } \\
\text { State the techniques used in the development of the short story, drama } \\
\text { and poetry; } \\
\text { Discuss the features of traditional poems, family/ clan praises, } \\
\text { work songs; } \\
\text { Trace historical background of traditional works. }\end{array}$ & $\begin{array}{l}\text { LIFE SKILLS } \\
\text { Problem solving } \\
\text { Effective communication } \\
\text { Empathy } \\
\text { Problem solving } \\
\text { Creative thinking } \\
\text { Effective communication } \\
\text { problem solving }\end{array}$ \\
\hline
\end{tabular}

\section{Methodology}

This study used a mixed-method design which combines qualitative and quantitative method. The study took place in the Shiselweni region of Swaziland. The study targeted secondary school siSwati teachers in the region. Twenty SiSwati teachers were randomly selected from 4 schools in the region, but only 19 teachers responded to the questionnaires. Twelve of these teachers were interviewed after the collection of the questionnaires. Instruments for data collection were semi - structured face to face interview and questionnaire. The questionnaire items were constructed using the closed ended items of the Likert type in which the respondents were asked to rank the items. The instrument was content validated by one lecturer of psychology in the University of Swaziland and one siSwati and English teacher in one of the secondary schools. All interviews were transcribed as soon as possible and were shown to the correspondence to cross check if they were in agreement with what was to be transcribed. The data collected was analysed using both qualitative and quantitative techniques. Qualitative data involving ideas and opinions were categorised into themes and analysed. 


\section{Findings and Discussions}

Research question 1: What are the perceptions of secondary school teachers on the cognitive life skills in the siSwati curriculum?

Table 2. Teachers levels of perception on cognitive life skills

\begin{tabular}{cccccc}
\hline \multirow{2}{*}{ Cognitive skills } & Number of teachers & Levels of teachers perception & NA & Ranking \\
\hline Decision making & $19(100 \%)$ & $8(42 \%)$ & $8(42 \%)$ & $3(16 \%)$ & 1 \\
Problem solving & $19(100 \%)$ & $5(26 \%)$ & $10(53 \%)$ & $4(21 \%)$ & 2 \\
Critical thinking & $19(100 \%)$ & $7(37 \%)$ & $7(37 \%)$ & $5(26 \%)$ & 3 \\
Total & $57(100 \%)$ & $20(35 \%)$ & $25(44 \%)$ & $12(21 \%)$ & \\
\hline
\end{tabular}

The data in Table 2 above shows that most of the teachers were aware of the decision making skill. There were $8(42 \%)$ teachers who were strongly aware and the other $8(42 \%)$ who are only aware of this skill which makes a total of $16(84 \%)$ teachers who were aware of the decision making skills. These findings make the decision making skill to rank number one amongst the other cognitive skills. The decision making skill is followed by problem solving skill with 5(26\%) teachers who were strongly aware and $10(53 \%)$ who were just aware making a total of $15(79 \%)$ teachers who were aware of decision making skills. The critical thinking skill comes last among the cognitive life skills, less teachers are aware of creative thinking skills only7(37\%) were strongly aware and 7(37\%) were just aware of this life skill making a total of 14(73\%)of teachers who were aware of critical thinking skills.

\section{Research Question 2: What are the perceptions of secondary school teachers on the personal life skills in the siSwati} curriculum?

Table 3. Teachers levels of perception on personal life skills

\begin{tabular}{|c|c|c|c|c|c|}
\hline \multirow{2}{*}{ Personal skills } & \multirow{2}{*}{ No. of teachers } & \multicolumn{3}{|c|}{ Teachers levels of perception } & \multirow{2}{*}{ Ranking } \\
\hline & & SA & A & NA & \\
\hline Self- awareness & $19(100 \%)$ & $4(21 \%)$ & $11(57 \%)$ & $4(21 \%)$ & 2 \\
\hline Coping with stress & $19(100 \%)$ & $7(37 \%)$ & $6(32 \%)$ & $6(32 \%)$ & 3 \\
\hline Coping with emotions & $19(100 \%)$ & $7(37 \%)$ & $10(53 \%)$ & $2(10 \%)$ & 1 \\
\hline Total & $57(100 \%)$ & $18(32 \%)$ & $27(47 \%)$ & $12(21 \%)$ & 3 \\
\hline
\end{tabular}

The data from Table 3 above indicates that a large number of teachers are aware of coping with emotions life skills with 7 $(37 \%)$ teachers who were strongly aware and 6(32\%) who were just aware making a total of $17(89 \%)$ teachers who were aware of this life skill. The next personal skill that teachers are aware of is self- awareness life skills with $4(21 \%)$ teachers who were strongly aware and 11(57\%) who were aware of the skills and this makes a total of $15(78 \%)$ teachers who were aware of the self -awareness skill. The last skill that teachers were aware of is coping with stress life skills only $7(37 \%)$ were strongly aware and $6(32 \%)$ were aware of the skill making a total of $13(68 \%)$ of teachers who were aware of coping with stress skills.

\section{Research Question 3: What are the perceptions of secondary school siSwati teachers on interpersonal life skills in the} siSwati curriculum?

Table 4. Teachers levels of perception on interpersonal life skills

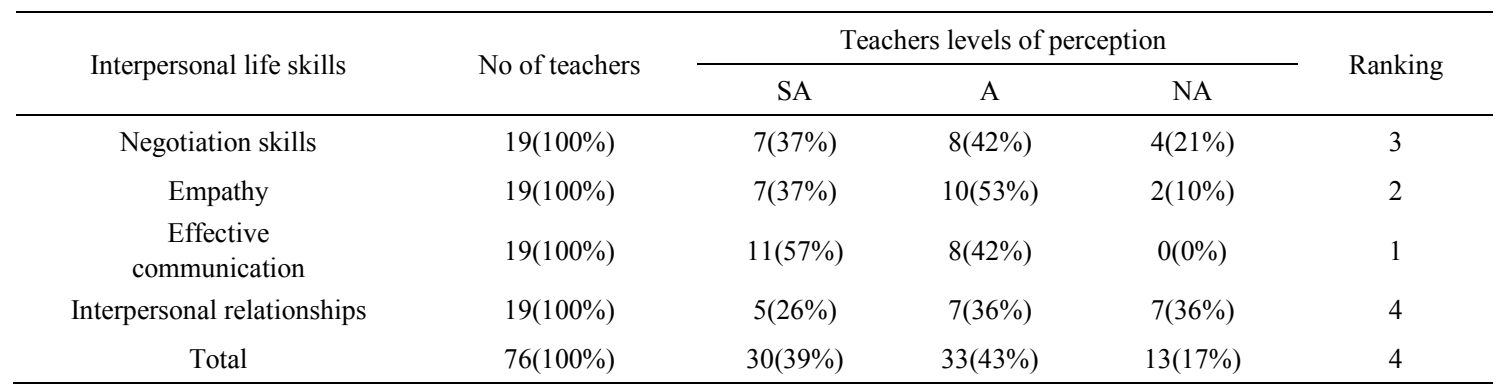


The data from Table 4 above reveals that all the teachers are aware of effective communication skills, while only a total of $17(89 \%)$ teachers were aware of the empathy skill with $7(37 \%)$ teachers who were strongly aware and 10(53\%) who were just aware of the skill. The next skill that teachers are aware of is the negotiation skills/ refusal skill with $7(37 \%)$ of teachers who were strongly aware and $8(42 \%)$ who were just aware of the skill making a total of $15(62 \%)$. The interpersonal relationship life skill was the last skill that the siSwati teachers were aware of , only 5(26\%) teachers were strongly aware of the skill and $7(36 \%)$ were just aware of the life skill which makes a total of $12(63 \%)$ teachers who were aware of the interpersonal life skills.

\section{Details of the Teachers Interview Analysis}

A total of twelve teachers were interviewed. The first three questions were meant to establish the teachers' awareness of life skills.

Question one "What is your understanding of psychosocial life skills?"

Below are some of the teachers' responses to the question:

I don't know, what are psychosocial life skills by the way?

I am not sure but I think they are the skills that help us deal with life situations.

They are the skills that we need in order to survive hardships.

\section{These are the skills that help us to live peacefully.}

Most of the teachers' responses to the questions showed that the siSwati teachers did not really know what life skills were because they could not even name them. They did not know what the cognitive life skills, the personal life skills and the interpersonal life skills are. The researchers had to really explain to them what these skills are. Some of the teachers said that they were aware of the life skills but they did not know how to group them.

Question five required the respondents to state what the major life skills promoted by the siSwati curriculum were. Question five "What major life skills does the siSwati curriculum promote among the learners?" These siSwati teachers responded to this question by stating that it must be the skills that the child needed to be able to think and make decision by themselves because they needed to make a lot of decisions to pass the examinations. When shown the different life skills they selected; decision making, critical thinking, effective communication and self- awareness. The researcher noted that the teachers mostly chose cognitive life skills $10(83 \%)$, except for self-awareness which is a personal skill and effective communication which is an interpersonal skill. When asked why they thought self- awareness is amongst the life skills mostly promoted, they responded by pointing out that it is important to boost the self-awareness of the learners if the purpose is to make them pass with 'flying colours'. The researcher noted that even in the questionnaire the teachers selected self-awareness as one of the mostly promoted life skill when answering the question on life skill promoted by the siSwati curriculum.

The siSwati teachers when being asked if they received formal training on life skills, the answer was negative, they pointed out that they had no formal training on life skills but at college the lecturers would sometimes discuss life skills in passing not in relation to teaching it in any subject. They pointed out that they rarely teach life skills to the learners and they find it challenging to teach life skills in class. They normally teach their planned lessons and a life skill topic would come up for instance on 'respect' and then the teacher would discuss the topic of respect with the learners not that they prepare lessons for life skills. They also pointed out that they needed educational workshops and a step by step teachers' manual/guide to assist them in the process of teaching and learning. The teachers cited the lack of time as the greatest challenge in the promotion of life skills in the schools.

Question six "How does the siSwati curriculum promote the skills you mentioned above?" This question required the siSwati teachers to give the teaching methods and styles they used in the promotion of the life skills mentioned above. The teachers said that they used the method which is commonly used when teaching, they just discuss as a class together.

One male teacher pointed out that it helped talking to the pupils as a class because you get to know what the pupils already know about the topic and also if they have experienced such a problem or if they know someone going through the same problem/ experience. The learner who has experienced such a problem would then tell the others what happened and how he/she overcame that problem. Learners learn better when they listen to one of them giving his/her testimony. The teacher would then add by teaching them skills to use to overcome such situations.

Most of the teachers said that it is much easier talking or discussing with the pupils concerning that topic while teaching them that life skill. One teacher mentioned that there life skills found in short stories that are prescribed in the siSwati curriculum which are decision making, effective communication interpersonal relationships and many more. The teacher can teach the life skill using the events from the short story as examples. According to the teachers' class meeting was the time for them to teach life skills.

The next question required siSwati teachers to state if they do invite guests to teach life skills to the learners in, the answer was negative and the reasons they gave are lack of money and time. They mentioned that the only time a person is invited to address the learners is during the morning assembly mostly pastors at least once a week. One head of department said, "If you invite someone to come and teach life skills to the learners, who is going to pay? The school doesn't have any money. "They said their major problem is that there is no time for life skills activities, they are only allowed the time allocated in the time table and there are examinations to think of. When asked if they tried siSwati debates and dramatization to promote life skills. The answer was No, they never tried these methods because there is no time and besides they were not taught how to use these 
methods to teach these life skills.

When asked if they thought the introduction of these life skills in the siSwati curriculum has had an impact on the learners' change of behaviour. The answer was No, they have not yet seen any positive change in the learners behaviour. One teacher even pointed out that it is like their behaviour is becoming worse; the points made by the teachers were;

- $\quad$ The learners drink intoxicating drinks a lot these days, cases of learners who are expelled from school or punished because they have been caught drinking alcohol is increasing.

- $\quad$ Some are smoking because of the kind of friends they have.

- $\quad$ Even girls are still dropping out of school because of pregnancy girls generally grow faster than boys. With girls falling pregnant every year, this is an indication that the introduction of life skills has no significant effect yet.

- Boys and girls are found around the corners of the school kissing.

- $\quad$ Some are stealing from other students' bags and even stealing the bags.

The reason for the life skill not having a positive impact in the learners is that they are not properly promoted. According to one teacher, she never teaches life skills in class because she does not know much about the subject, "How can you teach something you are not even sure of?" The teachers said that it would be better if they were given a step by step teachers guide to help them in teaching these life skills. They felt that may be if these life skills were properly taught to the learners, there would be observable change in behaviour amongst the learners. According to the respondents, the major constraint in integrating life skills into the siSwati lessons is that many teachers did not know how to integrate it. One teacher even asked if it is possible to deal with life skills without training. These findings prove that the learners are not taught some of the life skills especially the negotiation/refusal skill and other interpersonal skill, which maybe the reason why there is no observable change in the learners behaviour.

Question eight required teachers to give the learners attitude towards life skills. Question was "What is the pupils" attitude towards life skill topics in the siSwati subject?" Teachers said the learners have no problems with life skills teaching, they are actually excited when they have to talk about relationships, decision making and life in general "such topics are refreshing for them. The teachers believed that if life skills were taught correctly to the learners, they would really enjoy the lessons. One teacher even made an example of the talks that the learners normally got from the invited guests during assembly, "the students really enjoy these talks about choosing the right friends and making the right decisions in life, they would really enjoy having us siSwati teachers teaching them these life skills". The problem is lack of time the teachers felt that when teaching life skills time is wasted so they rather teach the material that is examinable because in the end the learners have to write tests.

One teacher even said that "it would be better if there is time allocated for the teaching of life skills because the learners can end up complaining that we are wasting their time with something that will never be tested or examined." This information from the teachers reveals that some of the teachers' attitude towards the life skills topics was negative because they did not know how to go about incorporating them in the actual teaching and learning process. But the learners do not seem to have a problem with life skills teaching because they enjoy having people addressing them on life skills issues during assembly, how then can they refuse listening to life skills lessons in class.

Question ten asked for the teachers recommendations towards the effective promotion of life skills in the subject. Question ten "What recommendations would you give for the effective promotion of life skills in the secondary schools?" This question was meant to find out the teachers ideas on what they think would be useful in promoting the life skills that are embedded in the siSwati curriculum. The teachers responded by pointing out that they felt that in order for them to be able to promote life skills in the learners there is need to deliberately make the teachers gain awareness about some of the ways in which life skills could be brought in the fore front of the teaching. This will help the teachers to equip the learners with the right life skills. The teachers added that since the teachers were not enlightened with the issues of life skills, educational work- shops should be organised where the teachers will be taught how to go about teaching the life skills they find in the curriculum. It was also gathered that teachers lack awareness even if some of them claim to have been trained on life skills at college or attended work-shops, they are not trained in the teaching of the life skills that are embedded in the siSwati curriculum. The teachers' recommendations could be summarised as follows;

- Make teachers aware of all the life skills that are embedded in the siSwati curriculum and how to incorporate them in the teaching and learning process.

- Organise educational work-shops to train teachers who are already out of college and those who are still training to know how to teach life skills.

- Provide proper training on life skills responsive curriculum in teacher training universities and colleges

- Distribute resources and life skills step by step teachers' guide to help them know how to teach the skills step by step.

In response to question eleven, where teachers were asked if there are questions that they felt were not addressed by the siSwati curriculum that would strengthen the discussion of life skills in the siSwati lessons. The teachers responded by saying that it would be good if they can be taught the different types of life skills as they are grouped, "we don't 
know the cognitive, the personal and interpersonal skills, we can end up promoting the same kind of skills and leaving out the other forms of life skills because we do not know them," said one female teacher. They suggested that enough time should be allocated to the teaching of life skills in the siSwati lessons not to teach life skills once a term like some teachers do.

The teachers also suggested that the topics found in the curriculum should address problems that are mostly occurring at that particular time, like this time the most persistence problem is negative peer pressure and substance abuse. The teachers pointed out the fact that the learners are punished now and again for love relationships, some girls even drop out of school because of unplanned pregnancies, some learners are punished and even suspended from school for taking alcoholic drinks, "these children get thirsty!" remarked one male teacher.

In response to question twelve, "What are the major causes of pupils dropping out of school, according to your understanding?", the teachers responded by pointing out unattended teenage pregnancy as the main cause. Girls generally grow faster than boys. The illicit men and boys take advantage of this and lure them into early sexual activity, which at times results into pregnancy. Some pupils even just opt out of school once they see that they are matured commented one teacher in one of the schools. Many cases of the child neglect or poor parental care were also reported as one the problems that cause school dropouts.

The increasing cases of young people involved in drinking alcohol and smoking is another problem related to peerpressure. In a society where drinking the of local brew "buganu" the marula drink is taken as a socialising affair and coupled with lack of regulatory laws, many people including young school going children have taken into drinking it and even smoking, observed one teacher. When asked whether there were school children involved in drinking alcohol and smoking. Teachers in one of the schools pointed out that drinking is a serious problem facing the school because the students always have money to buy alcohol from the drinking bars around town since the school is not far from town. Parents who have lots of money give their children too much money such that the child does not know what to do with it so they use the money to buy alcohol from town. 'I don't understand how these children enter these drinking bars because the age restriction is clearly written, how then do they sell them this alcohol?" remarked one teacher. The parents of learners who are caught drinking alcohol are called to school to discuss what is to be done to the child as disciplinary measures; the child is either given a heavy task to do as punishment or suspended from school for some weeks.

The siSwati teachers also mentioned that failing subjects is another cause, learners are allowed to repeat a class once and the second time they are told to try another school. Some students after failing the second time decide to give up school and either stay at home or go looking for jobs. This finding is an indication that cognitive life skills are not well promoted in the learners because these life skills would help the learners with their academic work.

The rampant poverty amongst many parents is also blamed for parents and guardians failure to provide their children with even the least required materials such as stationary. Some orphans who are sponsored by government find that they do not have money for 'top up' because there is no one to take care of them, so they drop out of school. Orphans are in most cases left to fend for themselves, heading families is a task that they are not prepared for given their tender age. This coupled with poverty makes such children lose interest in their studies and drop out. These children need to be taught personal life skills to help them cope with the stress and emotions they face.

The last question required teachers to suggest ways to reduce the number of school drop outs. To reduce the cases of school drop outs the teachers suggested that life skills teaching should be strengthened not only in the siSwati subject but in all the subjects. Skills like negotiation and refusal skill and effective communication should be taught to learners especially girls to refuse and get out of situations where they have to practice unsafe sex and get pregnant, "they should know that 'No means No' and to refuse to get involve in negative peer pressure," said one teacher. It would help to strengthen their cognitive life skills so that they pass their schoolwork, their personal skills would help them deal with stress and cope with emotions effectively. One teacher suggested that young girls who leave school because of pregnancy and those who get married need to be followed up and trained in these life skills. This will not only stop others from getting married early and from getting pregnant but also shows the concern education institutions have for the girl child.

The teachers also called upon parents who give their children excess money to cut down on the pocket money and give them money just enough for lunch. The issue of students who have expensive mobile phones where they watch videos and chat with their friends to the detriment of their studies is another problem that parents have to sort out by not giving their children these expensive mobile phones which end up disturbing students from their studies. Teachers also advised schools to form peer education committee/clubs to foster the promotion of life skills. Even though most schools visited feared to invite guest speakers because of financial implication but there is need to invite mentors and other guests to talk to the children. The schools do invite pastors to preach to the learners during assembly and that is the only time learners get to be taught about life skills by someone from outside school. Police officers would visit the schools at least twice a year to address the learners on safety measures to be used by the learners to stay out of prison.

\section{Discussion}

From the findings, it was observed that most of the teachers admitted to be aware of psychosocial life skills. The 
findings revealed that the life skills that are mostly promoted by the siSwati curriculum are mostly the cognitive life skills which are decision making, followed by problem solving and critical thinking. These are the skills that are mostly needed by the learners to be able to do well in their academic work. The personal life skill which is mostly promoted is self-awareness. The learners also need the other personal life skills which are coping with emotions and coping with stress so that they can survive the various challenges that they may encounter daily. The findings also showed that most of the teachers were aware of effective communication life skill, actually all the teachers $19(100 \%)$ were aware of this life skill. The other interpersonal life skills which are negotiation/ refusal skill and Empathy are not given much attention and yet they are very important in helping the learners in dealing with others and in handling different life situations they encounter. They can learn to negotiate their way out of negative peer pressure by refusing politely to join in some of their peers bad habits. The findings also revealed that siSwati teachers were not trained to integrate these life skills in their teaching they use their general knowledge because there is no teachers' guide to show them how to teach the lesson step by step. The teachers have not even been invited to educational work- shops to be trained to teach these life skills. The teachers suggested that they should be trained to teach the life skills and teaching guides be made available for them to use during life skills teaching.

WHO (1997) states that the implementation of life skills programmes requires the introduction of teaching methods that may be new to teachers and the success of the programme will depend very much on the availability of in-service training, as well as efforts to include training up the participatory learning in the teacher training college.

The siSwati teachers suggested that they needed training so that they can be able to integrate life skills in their lessons. In support of this idea, UNICEF (2012) states that there is a particular challenge in the development of sufficient human resources (both in terms of numbers and quality) for life skills education delivery. Many programmes have specific teacher training components and increasingly, this includes both in-service and pre-service training. Yet despite this, the demand for further training is not adequately addressing important elements for life skills education delivery, such as the psychosocial skills and attitudes of teachers themselves.

The UNICEF Evaluation Report (2012) suggests that, there should be clear guidelines on life skills education assessment that can support the integration of effective life skills education assessment into education systems, schools and classrooms. This is also supported by UNICEF (2005) in the study conducted in South Asia where it was discovered that the monitoring of classroom delivery quality usually did not occur. The use of cascade training and peer education methods were problematic and the participation of learners in programming was limited.

In this study it was further established that the learners received less class talks on life skills in the siSwati lessons. Kendra (2011) noted that the method used in the teaching and learning of life skills should be through active learning and participation using four basic components; practical activities, feedback and reflections, consolidation and reinforcement, practical application day-to-day life challenges. This observation is shared by UNICEF (1999) who argued that for effective skills based health education and life skills, teachers need to employ methods in the classroom that let young people model and observe the skills. Tobler (1992) noted that approaches to health education and life skills show that active participatory learning activities for students are the most effective methods of developing knowledge, attitudes and life skills. This therefore means that the problems of lack of awareness of life skills in the siSwati learners may not only be due to the number of class talks given or the involvement of teachers but also the methodology used in delivering the life skills.

The teacher could have dwelt on giving information and lecture methods, and disregard the more child-centred methods such as dramatization, role play, discussions. UNESCO (2000) also noted that the most effective methods of life skill development involved people in active, participatory learning experiences rather than passive ones.

This line of thought is supported by Nelson (2009) in his study where he states that creating role playing opportunities and scenario gives students a safe environment to practice being assertive. This approach is similar to the scaffolding of Vygotsky. Crain (2005) described role playing as part of the learning process from early childhood. Vygotsky (1978) discussing the zone of proximal development states that children learn best from an elder or more capable person guiding their efforts. Too often people forget that children are in an incredible learning phase and they are left to fumble through situations without specific guidance related to self-esteem, peer support and adult intervention. Most would agree that parents and educators alike must maintain a close, positive support system with clear frame work that allows trial and error while practising incremental decision making.

MacDevitt and Ormrod (2002) refer to Vygotsky's ideas and their implications to the classroom. They believe that the ideas can be addressed through role playing. Vygotsky thought that before children can perform tasks alone, they can perform them in collaboration with others, receiving some guidance or support. Teachers must directly teach children new concepts not wait for them to make their own discoveries. Powell (2004) noted that opportunities must be created to be supportive and to give tasks and challenges that raise self- esteem so that students may be able have success in school and develop self- motivation.

Gartrell (2004) supports the siSwati teachers' method of teaching life skills which is class meetings and discussions. Gartrell states that class meetings encourage reflection and sharing by children and teachers about their experiences, needs, concerns, problem and triumph. Those who have very specific personal direction and expectations and goals are sometimes more immune to the outside responses they may receive. Considerations are two fold, intrinsic and extrinsic variables affect each student differently. Psychosocial life 
skills learning programmes can provide a safety net for those in need and a springboard for those ready to expand their sense of self.

UNICEF (2012) in the Evaluation report points out that life skill education involves the use of the interactive and participatory teaching and learning methods, and experiential and activity- centred pedagogy. Example of interactive learning activities include: class discussion, brainstorming, role playing, games and simulations, case studies, debate and storytelling. According to UNICEF, this range of activities also helps to develop life skills, and is closely related to self-expression, promotion of emotional intelligence, cooperation, negotiation, examining or analysing different perspectives, constructive argument and problem solving. At the same time the activities are used to explore and develop content related knowledge, attitudes and skills. They bring new information into the classroom for young to engage with, as well as enable them to draw their own experiences.

The study also found out that siSwati teachers had no access to life skills materials, supplied by Ministry of Education and Sports and the centre coordinating tutors. This finding is supported by UNICEF (2012) when alluding to the fact that beyond the school system, data are limited and there is rarely a clear picture of life skills education coverage. According to UNICEF, this is compounded by the fact that, in the non- formal sector, life skills education is largely in the hands of non-governmental organisations and other generally small scale- providers with little coordination, reporting or quality assurance mechanisms.

This inaccessibility to adequate life skills materials by these schools explains the problems in non - awareness of life skills.

The study also discovered that assembly talks were the major means teachers used to promote life skills, followed by class meetings. More child centred methods like group discussions and peer teaching were least considered by the siSwati teachers. These findings agree with the observation by the teachers that they were positive to life skills programmes but were constrained by lack of time, coupled with lack of materials for teaching life skills. The implication is that life skills are given little or no time at all because assemblies and class meetings usually take a short time, and assemblies are held every week but the priests who are invited to preach to the pupils or talk to them about life come at least once a week. On the other hand, the class talks take place mostly twice a month in some of the schools visited and quite often many issues are discussed during the assemblies. On lack of time, one teacher reported that the overloaded teaching time table, coupled with the pressure from the administration for teachers to complete the syllabi on time, renders the practice and teaching of life skills almost impossible.

These findings are in agreement with Francis (2007) who observed that academic learning and vocational education are considered more important for the learners by teachers and the school administrators rather than life skills. The implication is that even if time and funds were available for life skills, the schools could probably channel such funds to other school programmes other than for the promotion of life skills. Until the system of education is changed from being examination oriented or the life skills taught and examined schools may not devote enough time to life skills education.

According to Parson et al (1988), a programme that has a component of on-going assessment of its use and impact offers scope for keeping in touch with changing priorities, and is more likely to be modified and maintained over time. UNICEF(2012) however, recommends that life skills education knowledge content should, however possible, be integrated within the school curriculum so that it is not perceived as an add-on that contributes to curriculum overload but as a core curriculum component that can be assessed within the standard assessment processes.

It was further established from the research that the involvement of parents and invited guests in the promotion of life skills among pupils was low. Mangrulker, Whitman and Posner (2001) noted that programme providers for life skills programmes require a blend of professional and personal qualities. Some individuals bring these to the job and others must be trained to acquire them. Usually life skills programmes are offered by social workers, counsellors, teachers, and psychologists or other health care providers. It is essential that the leader is a role model who is successful or competent, possesses high status, and has control over rewarding resources.

This idea is supported by Bandura (1977) who pointed out that health care providers often fulfill these expectations, as do many teachers, community leaders and parents. However many adults will need to unlearn authoritarian and didactic approaches to learn to become effective providers. UNICEF (2001) recommended the involvement of learners, parents and community workers in the design and implementation of school health programmes. They also noted that involving a large spectrum of participants makes them likely to demonstrate commitment to and ownership of the programme, which thus enhances sustainability and effectiveness. UNICEF (2005) argues that the rational implementation of in-school life skills based education should actively involve stakeholders and build support among ministerial and civil society leadership. The goal should be to create life skills now and work for incremental improvement over time. While Donnell et al, (1998) argued that a curriculum combined with youth community service reduces risk behaviours such as fighting, early sexual behaviour and substance use more effectively than a curriculum alone.

Opio (2010) points out that a school is a small unit of a large community, thus involvement of other members of the community in the education of children, would go a long way in reducing vices in our society, such as early marriages, defilement, teenage pregnancies, negative attitude to education. Vygotsky (1987) noted that new levels of 
understanding begin at an interpersonal level; originally between infant and an adult and then through continuous social interaction. This implies that the social environment of the child has a strong influence on his/her cognitive and effective skills and can be enhanced by more extensive, structured high quality interaction with others.

One example of a life skill programme that make use of the members of the community is the American Indian life skills Development which is a school based suicide prevention curriculum designed to address this problem by reducing suicide prevention curriculum designed to address this problem by reducing suicide risk and improving protective factors among American Indian adolescents aged between 14 to 19 years old.

The Zuni life skills development (2007), states that lessons are delivered by teachers working with community resource leaders and representatives of the local social services agencies. This team-teaching approach ensures that the lessons have a high degree of cultural and linguistic relevance even if the teachers are not Native American or not of the same tribe as the students. For example the community resource leaders can speak to students in their own language to explain important concepts and can relate curriculum materials and exercises to traditional and contemporary tribal activities, beliefs, and values. A school counsellor (typically of the same tribe) serves as the on-site curriculum coordinator.

The Zuni Life Skills Development Curriculum was developed with cultural components relevant to the people of the Zuni Pueblo in New Mexico and was tested and evaluated with that population. The Zuni curriculum served as the basis for the broader American Indian life Skills Development that is now in use, which can be used with other American Indian populations when implemented with appropriate and culturally specific modifications.

The findings revealed that the important structures in the promotion of life skills such as debating clubs, role playing, writers club, career guidance were not very active in the schools. Career guidance, writers clubs and debating clubs not only in-still life skills in pupils but also helps improve pupils' academic performance. The underutilization of such structures partly explains the declining academic performance of pupils in some of these schools. The teachers explained that they did not consider debate in siSwati important because the learners are first language speakers, they do not have a problem conversing in siSwati and besides they wouldn't know what to assess in this kind of a debate.

The researcher was informed that debates only took place in the English department where students even enter debate competitions with other schools. The siSwati teachers said they had no idea how they can go about organising these clubs and did not think that the siSwati department could have such programmes. This is depriving the learners of vital life skills being taught in their own language where they would be comfortable because they would be discussing in their mother tongue.

\section{Conclusions}

The following general conclusions were drawn from the findings of the study. The findings show that there is need to integrate life skills topics in the siSwati lessons, beginning with including the life skills training in teacher training colleges and providing in- service training for the teachers who are already in the field. The interviews with the teachers showed that even though teachers were not trained in life skills teaching, they tried to tackle life skills issues during their teaching. The study also revealed that some challenges faced by the teachers in implementing life skills in the teaching and learning process include, lack of training, lack of time and lack of teaching materials like teachers' guide.

\section{Recommendations for Action}

From the preceding summary and conclusions, the following recommendations are made: All teachers should be involved in the promotion of life skills among pupils, so as to ensure adequate attention to all learners. There is need to supply schools with life skills educational materials such as teaching guides so as to expose more pupils to life skills activities. Academics should also be balanced with extracurricular activities involving the use of structures like debating club, music and drama clubs, writers club that are child centred for promotion of life skills. Work-shops for teachers should be organised and supported by either inviting a resource person or facilitating teachers to attend the course elsewhere. Peer education committee/ clubs could be created and where possible invite mentors and other guests to talk to pupils. Consumption of alcohol and smoking by teenagers should be discouraged through sensitising them about the dangers of alcohol and smoking or the government enacting laws that will stop the youth from consuming alcohol.

Structures such as debating clubs, writers clubs, health and straight talk clubs that promote life skills should be put to maximum use, through regular practice and competitions. Parent-teacher, pupil-teacher and parent-pupil interactions should be encouraged, through school visitations, parent-teacher associations, extra-curricular competitions in which parents could be invited. Through such interactions the two parties would appreciate the importance of education and in particular life skills. A more focused life skills education programme for pupils in disturbed areas could be drawn by establishing the common psychological problems pupils face. On the challenges faced by teachers in the promotion of life skills the recommendations are; life skills programmes should be either integrated in the teaching and learning process and be examined or life skills programmes be allocated special time on the teaching time table or core life skills education subject be introduced in the school curriculum. The Ministry of Education and Sports should step up its supervisory role on the progress of life skills education by forming life skills committees/ clubs in schools and also fund the life skill programmes. 
The Ministry of Education and Sports should consider organising in- service workshops for siSwati teachers to be trained in teaching life skills and also purchasing life skills teaching guides to assist them in the implementation of life skills in the classroom. To cultivate the culture of reading and writing, writing and debating competitions could be introduced and supported in the siSwati classroom.

\section{REFERENCES}

[1] Bandura, A. (1977). Social Learning Theory. Eaglewood Cliffs, NJ: Prentice-Hall.

[2] Crain, W. (2005).Theories of Development: Concepts and Applications. Upper Saddle River, NJ: Prentice Hall.

[3] Education for Change (EFC) (2012). UNICEF Final Draft: Global Life Skills Education and Evaluation, United Kingdom: Education for Change Ltd.

[4] Gartrell, D. (2004). 5 Minds for the future. Boston: Harvard Business Press.

[5] Macdevit, N., Ormard, J. (2002).Child Development and Education. Upper saddle River, NJ: Merril Prentice Hall.

[6] Mangrulker, L., Whitman, V., Posner, M. (2001). Life Skills Approach to Child and Adolescent Healthy Human Development. Pan- American Health Organization.

[7] Parson, R., Brown, B., Martimor, J. (2002). Adolescents Preparation for the Future: Perils and Promise. New York: Blackwell.
[8] Powell, K. (2004). Developmental Psychology of Adolescent Girls: Conflicts and Identity Issues, fall, v125 n1.

[9] Shriver, T. \& Weissbergh, R.(2005). No Emotional Left Behind. New York Times, 8/16/05.

[10] Stipek, D., Miles, S. (2006). Contemporaneous and Longitudinal Associations between Social behaviour and Literacy achievement in a sample of low income elementary Tobler, N. (1992). Drug prevention programs can work: Research findings. Journal of Drug Issues, 16, 537-567 UNICEF. (2005). Life Skills-Education in South Asia, Bangladesh: Dhaka UNICEF.

[11] United Nations Children's Fund (UNICEF. (2007). Stocktaking of Life Skills- Based Education. UNICEF.

[12] UNICEF (2012) Evaluation Report: Global Evaluation Report of Life Skills Education Programmes, New York: Evaluation Office.

[13] Vygostky, L.S. (1978). Mind in Society. Cambridge M A: Harvard University Press.

[14] WHO. (1994).Mental Health Education, School Health Services, Mental Disorders in infancy and childhood in Adolescence. Gov't Doc\#: WHO/MNH/PSF/93.3 Rev. 1.

[15] WHO. (1997). World Health Organization. Life Skills Education for children and Adolescents in schools Programme on Mental Health Organization. Geneva: WHO.

[16] WHO. (1999). Partners in Life Skills Education Conclusions from a United Nations Inter-agency Meeting. Geneva: WHO, 1999 (WHO/ MNH/ MHP/99.2)

[17] WHO. (2003). Skills for health. Geneva: WHO. 